\title{
Preparation of Gold Tailings-incorporated Composite Cementitious Materials and the Mechanism of Chlorine Solidification
}

\author{
Xiaoping Tian ${ }^{1,2,3}$, Jiayu Zhan ${ }^{1}$, Changlong Wang ${ }^{3,4,5,}{ }^{*}$ and Xiaowei Cui ${ }^{6}$ \\ ${ }^{1}$ State Key Laboratory of Solid Waste Reuse for Building Materials, Beijing Building Materials Academy of Science Research, Beijing \\ 100041, China \\ ${ }^{2}$ Faculty of Engineering, Universiti Malaysia Sabah, Kota Kinabalu Sabah, 88400, Malaysia \\ ${ }^{3}$ School of Civil Engineering, Hebei University of Engineering, Handan Hebei Province, 056038, China \\ ${ }^{4}$ Jiangxi Key Laboratory of Mining Engineering, Jiangxi University of Science and Technology, Ganzhou Jiangxi Province 341000, China \\ ${ }^{5}$ Tianjin Sunenergy Sega Environmental Science \& Technology Co. Ltd, Tianjin 300000, China \\ ${ }^{6}$ Shaanxi Key Laboratory of Comprehensive Utilization of Tailings Resources, Shangluo University, Shangluo Shaanxi Province 726000 , China
}

Corresponding Author Email: *baistuwong@139.com

\begin{abstract}
To comprehensively utilize the industrial solid waste gold tailings (GTS), the experiment in this study takes the mechanically and thermally activated GTS as the main raw material to prepare composite cementitious materials (CCM). Mechanical property testing, X-ray diffraction (XRD), flourier transform-infrared spectroscopy (FT-IR), and scanning electron microscope (SEM) and other testing methods are adopted in the paper to study the preparation of GTS-incorporated CCM, the types of hydration products and the mechanism of chlorine solidification. The results show that for the CCM mortar blocks prepared by GTS powder that had been ground for $60 \mathrm{~min}$ and then thermally activated at $750{ }^{\circ} \mathrm{C}$, their $56 \mathrm{~d}$ compressive strength can reach $41.7 \mathrm{MPa}$, which has exerted a good effect on chlorine solidification. The ability of $\mathrm{C}_{3} \mathrm{~A}$ and $\mathrm{C}_{4} \mathrm{AF}$ in the $\mathrm{GTS}$ incorporated CCM to combine with the chloride ions had been enhanced, which had promoted the formation of friedel salt (FS). At the same time, the addition of active GTS powder generated more hydration products, C-S-H gels and ettringite (AFt), which had enhanced the material's ability to adsorb chloride ions, and the formation of a large amount of hydration products had increased the compactness of the mortar blocks, thereby improving the mechanical strength of the samples.
\end{abstract}

Keywords: gold tailings; composite cementitious materials; chloride ions; friedel salt; ettringite

Received: April-04-2019, Accepted: June-20-2019, https://doi.org/10.14447/jnmes.v22i3.a05

\section{INTRODUCTION}

Corrosion of steel bars is a main cause for the durability damage of reinforced concrete structures. Many studies have shown that in the case of concrete being alkaline, the steel bars won't corrode due to the existence of oxidation protective films [1-3]; but if the content of free chloride ions in the concrete is relatively high, the chloride ions would strongly promote the corrosion reaction, damage the protective films, and accelerate the corrosion of the steel bars, therefore, the solidification of chloride ions is particularly important for concrete. For this reason, domestic and foreign scholars have studied the process of chloride ions invading concrete [4], the mineral compositions of the admixtures and the cementitious materials [5], and the solidification effect of hydration reaction products on the chloride ions [6]; among these studies, the research on the solidification effect of mineral admixtures on the chloride ions is the most [7-9]. In terms of the types of mineral admixtures, solid wastes such as fly ash, slag, coal gangue and steel slag have been studied more, and the research shows that the adding such materials into the concrete can improve its internal structure and performance, and enhance the later stage strength, durability and impermeability of the concrete [10-13]. The above research generally believes that the with the improvement of the mechanical properties of the cementitious material, its durability would be better, however, this inference is not scientific; moreover, there's a lack in the re- search of the microstructure of the cementitious materials prepared by different admixtures, the mechanism of solidification, and the types of the mineral admixtures. In early 2018, China's gold mine reserves were 12,167 tons, ranking the second in the world. As a consequence, gold mining has resulted a lot of tailings that are difficult to handle, which has increased the burden on China's environmental protection. Due to the problems such as the reactivity of cementitious materials, the large mortar content and the technical problems of GTS, unlike slag, fly ash, or coal gangue, most GTS cannot be properly used. At present, most GTS are used for gold recycling, ceramsite preparation, baking-free bricks, or cement mixtures, etc. Mineral-based admixtures are powder materials that mainly took active $\mathrm{SiO}_{2}, \mathrm{Al}_{2} \mathrm{O}_{3}$ and other effective minerals as the main components, they have the potential hydraulicity and pozzolanic reactivity [14]. Therefore, according to other solid waste treatment and utilization methods, this study attempts to make full use of GTS's characteristics of high silicon and aluminum contents and apply mechanical activation and high temperature calcination to activate the active $\mathrm{SiO}_{2}, \mathrm{Al}_{2} \mathrm{O}_{3}$ and other active mineral components in the tailings, so as to study the chloride ion solidification ability and solidification mechanism of cement materials incorporated by single GTS powder activated different activation methods, thereby providing a reference for the proper use of GTS as mineral admixtures in improving the durability of concrete. 


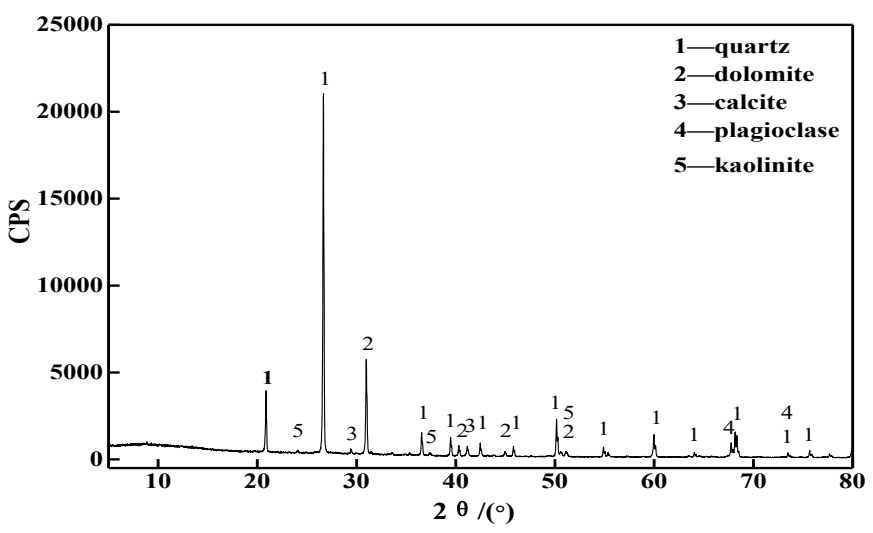

Figure 1. XRD spectrum of GTS

\section{MATERIALS AND METHODS}

\subsection{Materials}

(1) GTS. The chemical composition is shown in Table 1, from which we can see that the main component of GTS is $\mathrm{SiO}_{2}$ with a content as high as $80.74 \%$, followed by other components such as $\mathrm{Al}_{2} \mathrm{O}_{3}, \mathrm{CaO}$, and $\mathrm{MgO}$, all of which are high-silicon content mineral materials. The particle size of the GTS was distributed between $20 \mathrm{um} \sim 200 \mathrm{um}$, the yield of GTS with a particle size less than $0.15 \mathrm{~mm}$ was $75.24 \%$ (see Table 2). The mineral composition of GTS is quartz, dolomite, calcite and a small amount of kaolinite and plagioclase (see Fig.1).

(2) Cement (OPC). 42.5 ordinary Portland cement (OPC) with a specific surface area (SSA) of $355 \mathrm{~m}^{2} \cdot \mathrm{kg}^{-1}$ was adopted in the experiment, its chemical composition is shown in Table 1. The initial setting time of the OPC was 125 minutes, the final setting time was 220 minutes, and the water consumption of standard consistency is $24.2 \%$ (see Table 3).

(3) Sand: ISO standard sand.

\subsection{Methods}

\subsubsection{Sample preparation}

(1) Mechanical grinding. GTS was dried until the moisture content

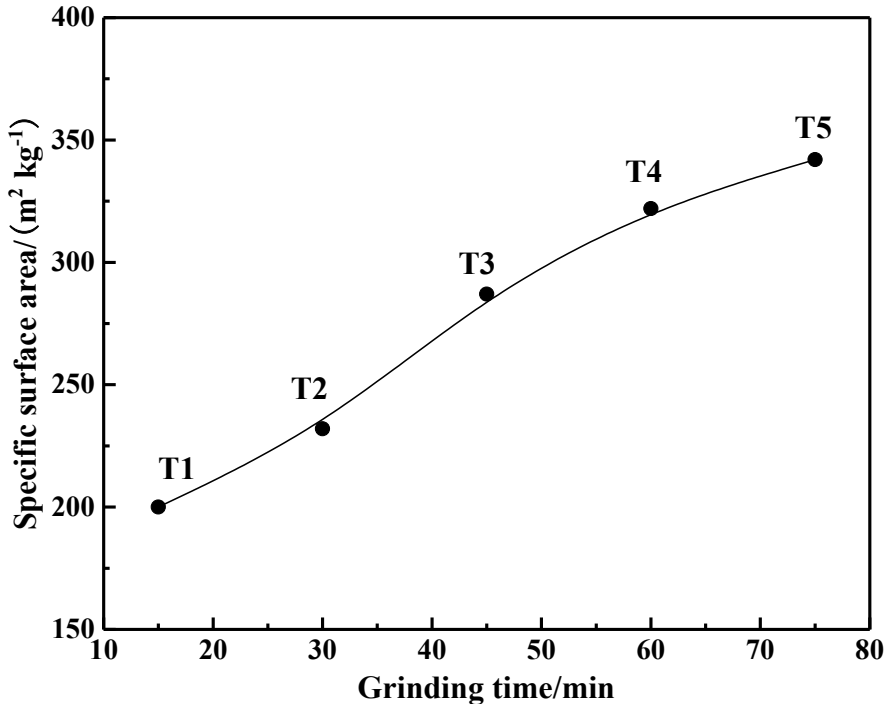

Figure 2. Relationship between grinding time and SSA of GTS

was less than $1 \%$ and then ground by a $5 \mathrm{~kg}$ laboratory ball mill $(\mathrm{SM} \varphi 500 \mathrm{~mm} \times 500 \mathrm{~mm})$, the grind time and the corresponding specific surface area are shown in Fig. 2.

(2) High-temperature calcination. The grinding GTS were put into a muffle furnace and subject to thermal activation process for 1 hours at $300{ }^{\circ} \mathrm{C}, 450{ }^{\circ} \mathrm{C}, 600{ }^{\circ} \mathrm{C}, 750{ }^{\circ} \mathrm{C}$, and $900{ }^{\circ} \mathrm{C}$, respectively; then the samples were taken out, cooled naturally, and labeled H1, H2, H3, H4, H5, respectively.

(3) Preparation of paste and mortar test blocks. GTS powders that were activated by different methods were selected to prepare 30 $\mathrm{mm} \times 30 \mathrm{~mm} \times 50 \mathrm{~mm}$ paste test blocks and $40 \mathrm{~mm} \times 40 \mathrm{~mm} \times 160 \mathrm{~mm}$ mortar test blocks according to the ratio listed in Table 4 . The concentration of $\mathrm{Cl}^{-}$in the solution was $0.5 \mathrm{~mol} \cdot \mathrm{L}^{-1}$. After molding, all test blocks were put in a standard curing box at a temperature of $(20 \pm 2){ }^{\circ} \mathrm{C}$ and a humidity of not less than $95 \%$; after cured for $4 \mathrm{~h}$, the molds were removed and the samples were cured continuously under the standard curing conditions until the specified curing age.

Table 1. Chemical compositions of main materials (wt. \%)

\begin{tabular}{|c|c|c|c|c|c|c|c|c|c|c|}
\hline Materials & $\mathrm{SiO}_{2}$ & $\mathrm{Al}_{2} \mathrm{O}_{3}$ & $\mathrm{TiO}_{2}$ & $\mathrm{Fe}_{2} \mathrm{O}_{3}$ & $\mathrm{CaO}$ & $\mathrm{MgO}$ & $\mathrm{MnO}$ & $\mathrm{SO}_{3}$ & $\mathrm{~K}_{2} \mathrm{O}$ & Loss \\
\hline GTS & 80.74 & 2.45 & 0.07 & 1.23 & 5.27 & 1.39 & 0.08 & 0.08 & 0.38 & 6.09 \\
\hline $\mathrm{OPC}$ & 21.80 & 4.55 & - & 3.45 & 64.40 & 2.90 & - & 2.45 & - & 1.27 \\
\hline \multicolumn{11}{|c|}{ Table 2 . Sieving results of GTS } \\
\hline \multicolumn{3}{|c|}{ Sieve size $/ \mathrm{mm}$} & & 4.75 & 2.36 & 1.18 & 0.60 & 0.30 & 0.15 & -0.15 \\
\hline \multicolumn{3}{|c|}{ sieve residue/g } & & 0.00 & 0.00 & 0.00 & 0.00 & 8.80 & 115.00 & 376.20 \\
\hline \multicolumn{3}{|c|}{ grader retained percentage $/ \%$} & & 0.00 & 0.00 & 0.00 & 0.00 & 1.76 & 23.00 & 75.24 \\
\hline \multicolumn{3}{|c|}{ Accumulated retained percentage $/ \%$} & & 0.00 & 0.00 & 0.00 & 0.00 & 1.76 & 24.76 & - \\
\hline
\end{tabular}

Table 3 Physical properties of OPC

\begin{tabular}{|c|c|c|c|c|c|c|}
\hline \multirow{2}{*}{$\begin{array}{l}\text { Fineness(residue on } \\
80 \mu \mathrm{m} \text { sieve) } / \%\end{array}$} & \multirow{2}{*}{$\begin{array}{c}\text { Normal consisten- } \\
\text { cy } / \%\end{array}$} & \multicolumn{2}{|c|}{ Setting time $/ \mathrm{min}$} & \multirow{2}{*}{ Stability } & Flexural strength /MPa & Compressive strength / $\mathrm{MPa}$ \\
\hline & & Initial setting & Final setting & & $3 d \quad 28 d$ & $3 d \quad 28 d$ \\
\hline 21.09 & 26.4 & 158 & 204 & qualified & 8.6 & 57.3 \\
\hline
\end{tabular}

Table 4 Mix proportions of OPC paste and mortar

\begin{tabular}{|c|c|c|c|c|c|}
\hline \multirow{2}{*}{ Sample } & \multirow{2}{*}{ Water binder ratio } & \multicolumn{4}{|c|}{ Mix proportions $/ \%$} \\
\hline & & OPC & mechanically activated GTS powder & composite activated GTS powder & sand \\
\hline A1 & & 100 & - & - & - \\
\hline B1 & 0.4 & 70 & 30 & - & - \\
\hline $\mathrm{C} 1$ & & 70 & - & 30 & - \\
\hline A2 & & 100 & - & - & 300 \\
\hline B2 & 0.5 & 70 & 30 & - & 300 \\
\hline $\mathrm{C} 2$ & & 70 & - & 30 & 300 \\
\hline
\end{tabular}



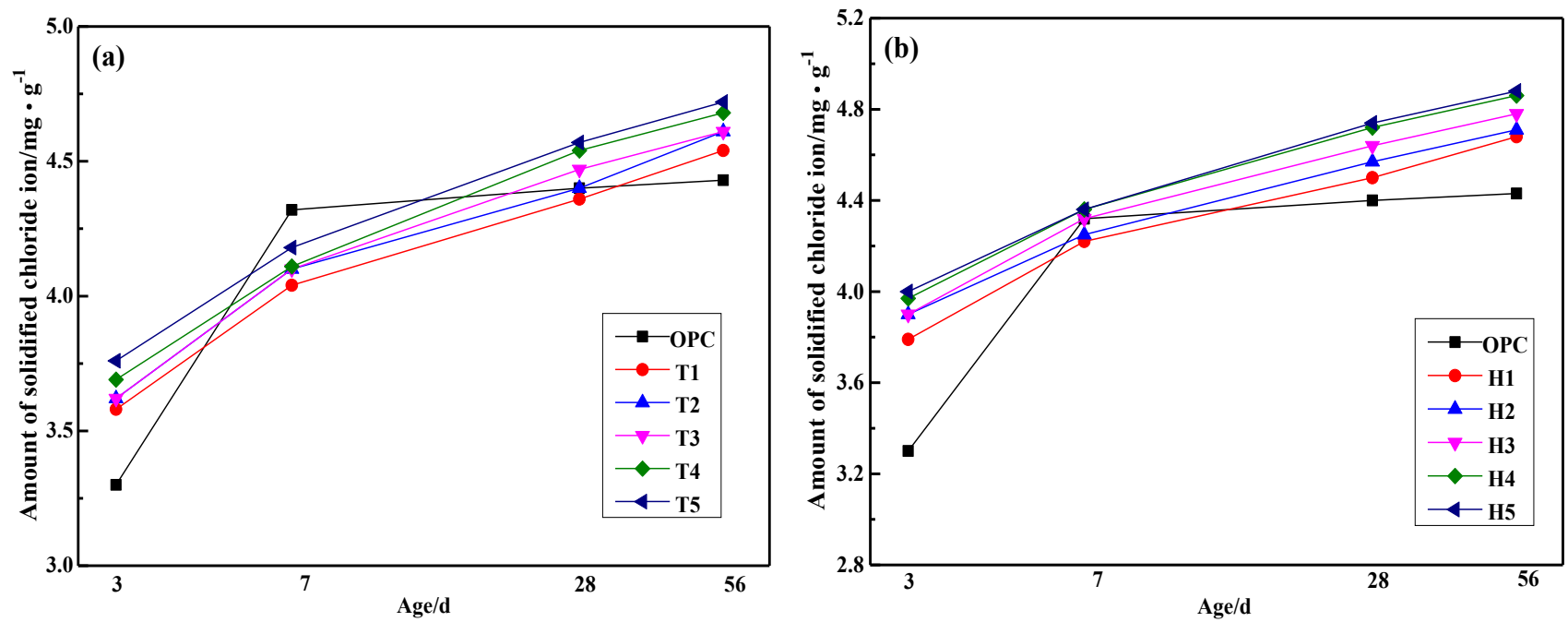

Figure 3. The diagram of Cl- curing ability of composite cementitious materials, (a)-mechanically activated GTS powder; (b)-thermally activated GTS powder
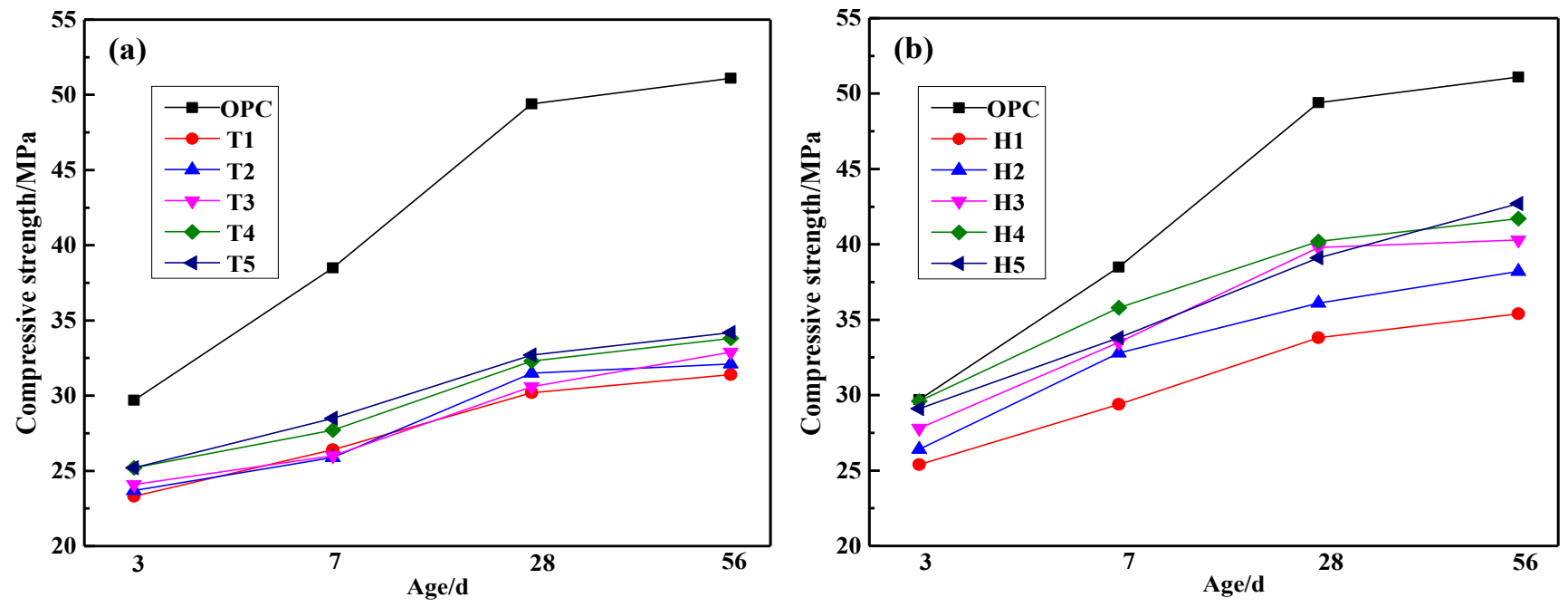

Figure 4. The diagram of compressive strength of composite cementitious material mortar blocks, (a)-mechanically activated GTS powder; (b)thermally activated GTS powder.

\subsubsection{Performance characterization}

The mechanical properties of the mortar test blocks were tested according to the GB/T17671-1999 Method of Testing Cements - Determination of Strength, and the YAW-3000 microcomputer controlled electro-hydraulic servo pressure tester was adopted for the test. The paste samples were processed according to P.R.C industrial standard JTJ 270-98 Testing Code of Concrete for Port and Waterway Engineering, test samples of corresponding ages were smashed and soaked in absolute ethanol for 7 days to terminate the hydration, and then were dried in an oven at $105 \pm 5^{\circ} \mathrm{C}$ for 2 hours. After that, about $30 \mathrm{~g}$ samples were taken and ground until all powder can pass through the $0.63 \mathrm{~mm}$ sieve, and then the samples were put in a dryer for later use. After that, about $20 \mathrm{~g}$ of the dried powder samples were weighed (accurate to $0.01 \mathrm{~g}$ ) and put into a conical flask, $200 \mathrm{ml}$ distilled water was added, and the conical flask was shaken vigorously for $2 \mathrm{~min}$, then the solution was soaked for 24 hours, and the filtrate was taken.
The solidification ability of the solidified paste test blocks of the cementitious materials is represented by the solidification amount $\mathrm{R}_{\mathrm{cl}}=\mathrm{C}_{\mathrm{t}} \mathrm{C}_{\mathrm{f}} ; \mathrm{C}_{\mathrm{t}}$ is the total content of $\mathrm{Cl}^{-}$in the sample and it's determined by the aqueous solution containing $\mathrm{Cl}^{-}$during the sample preparation process. In this test, the total $\mathrm{Cl}^{-}$content in the paste sample was $7.091 \mathrm{mg} \cdot \mathrm{g}^{-1}$, and the free $\mathrm{Cl}^{-}$content $\mathrm{C}_{\mathrm{f}}$ in the sample was calculated according to the filtration method of JTJ 270-98 Testing Code of Concrete for Port and Waterway Engineering, the formula is as follows:

$$
\mathrm{C}_{\mathrm{f}}=\frac{\mathrm{M}_{\mathrm{AgNO}_{3}} \times \mathrm{V}_{\mathrm{AgNO}_{3}} \times 35.453}{\mathrm{G} \times \frac{\mathrm{V}_{3}}{\mathrm{~V}_{4}}}
$$

In the formula: $C_{t}$ is the total amount of chloride ions in the samples, the value is $7.091 \mathrm{mg} \cdot \mathrm{g}^{-1} ; C_{f}$ is the amount of free chloride ions, the 
unit is $\mathrm{mg} \cdot \mathrm{g}^{-1} ; M_{A g N O 3}$ is the molar concentration of titrant silver nitrate, the value is $0.02 \mathrm{~mol} \cdot \mathrm{L}^{-1} ; V_{A g N O 3}$ is the volume of silver nitrate consumed in the titration, the unit is $\mathrm{mL} ; V_{3}$ is the amount of extracted filtrate in the test, the unit is $\mathrm{mL} ; V_{4}$ is the amount of distilled water added when soaking the samples, the unit is $\mathrm{mL}$; $G$ is the weight of the sample, the unit is $\mathrm{g}$.

\section{RESULTS AND DISCUSSION}

3.1 Effect of activation process on the properties of cementitious materials

Fig. 3 and Fig. 4 respectively show the amount of solidified chloride ions of the cementitious material incorporated by GTS powder and its compressive strength. From Fig. 3(a) we can see that the incorporation of ground GTS powder had improved the chloride ions solidification ability of the OPC material, the solidification ability increased with the increase of the fineness of the GTS powder, and the curve of the amount of solidified chloride ions showed a gradual increase trend. At age $3 \mathrm{~d}$, the OPC material showed a stronger ability to solidify chloride ions than pure OPC, indicating that GTS powder has a certain solidification ability on $\mathrm{Cl}^{-}$in the initial stage, and GTS powder might have adsorbed the chloride ions [15-20]. However, at age $7 \mathrm{~d}$, the chloride ions solidification ability of the OPC material was not as good as that of the pure OPC, however, with the progress of the hydration reaction, the role of the GTS powder had exerted in the later stage of the hydration reaction; from the figure we can see that for the OPC material containing GTS powder, the 28 $\mathrm{d}$ and $56 \mathrm{~d}$ chloride ions solidification ability was higher than that of pure OPC, and the solidification continued to develop, which contributed to the solidification of chloride ions.

It can be seen from Fig. 3(b) that the amount of solidified $\mathrm{Cl}^{-}$increased with the increase of the thermal activation temperature, from $300{ }^{\circ} \mathrm{C}$ to $750{ }^{\circ} \mathrm{C}$, the amount of solidified $\mathrm{Cl}^{-}$showed a gradual increase, while from $750{ }^{\circ} \mathrm{C}$ to $900{ }^{\circ} \mathrm{C}$, the trend became gentle. Compared with OPC materials containing GTS powder that was activated by mechanical grinding, the $\mathrm{Cl}^{-}$solidification ability of OPC materials of different ages was improved further. At this time, compared with pure OPC, the $28 \mathrm{~d} \mathrm{Cl}^{-}$solidification amount of OPC material was increased from $4.40 \mathrm{mg} \cdot \mathrm{g}^{-1}$ to $4.72 \mathrm{mg} \cdot \mathrm{g}^{-1}$, while for pure OPC, the $28 \mathrm{~d}$ $\mathrm{Cl}^{-}$solidification amount $\left(4.40 \mathrm{mg} \cdot \mathrm{g}^{-1}\right)$ was basically the same with the 56d amount. The above data proved that the activated GTS powder had certain pozzolanic activity, it participated in the reaction in the OPC material, and had a good promotive effect on solidification of chloride ions. It indicates that, adopting thermal activation based on the mechanical grinding activation method can better exert the reactivity of GTS powder, greatly increasing the amount of solidified chloride ions, especially in the later stage of the hydration reaction. In addition, from the reactivity of GTS powder in Fig. 3 we can see that, the composite activation process had obviously increased the reactivity of GTS powder, especially when the thermal activation condition was $750{ }^{\circ} \mathrm{C}$, the 56 compressive strength of the mortar blocks reached a maximum of 41.7 $\mathrm{MPa}$, then the continued temperature increase caused the reactivity to decrease.

\subsection{XRD analysis}

Fig. 5(a) and Fig. 5(b) are the spectra of different age hydration products of cementitious materials containing GTS that were activated by different methods. In $3 \mathrm{~d}$ phase analysis, the value of $2 \theta$ was in the
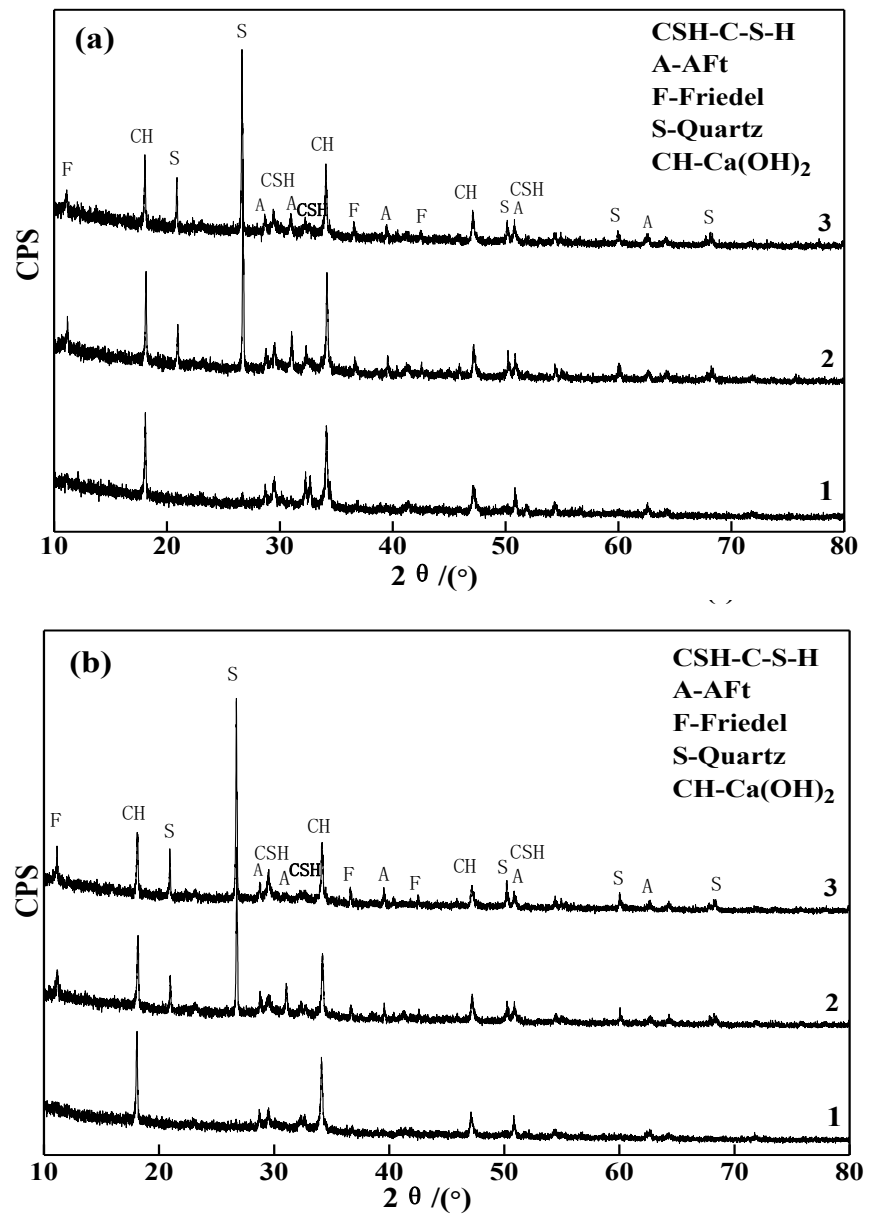

Figure 5. XRD patterns of hydration products of composite cementitious materials at various ages. (a)-3d; (b)-56d; (1)-OPC; (2)mechanically activated GTS powder; (3)-thermally activated GTS powder.

range of $25^{\circ}-35^{\circ}$, from the characteristics of the peaks it can be inferred that the main minerals were ettringite (AFt) and $\mathrm{C}-\mathrm{S}-\mathrm{H}$ gels, indicating that the $\mathrm{C}_{3} \mathrm{~A}$ and $\mathrm{C}_{4} \mathrm{AF}$ in the cement clinker and the $\mathrm{CaSO}_{4}$ in the gypsum had jointly participated in the hydration reaction. Such amorphous and low-crystallinity minerals had formed in huge amount in the earlystage hydration products, therefore, the phenomenon of wide "convex hull"-shaped background had appeared in the spectrum. A few friedel salt (FS) peaks can also be seen at other diffraction angles. With the progress of the hydration process, for the solidified cementitious material containing activated GTS powder, enhanced diffraction peaks of FS appeared in the later stage, indicating that the amount of FS produced by the chemical combination of minerals such as $\mathrm{C}_{3} \mathrm{~A}$ and $\mathrm{C}_{4} \mathrm{AF}$ and the chloride ions had increased, the incorporation of activated GTS powder had promoted the formation of FS [21, 22]. At the same time, it can be seen from the comparison of hydration age that, in the later period of the hydration reaction, the intensity of the characteristic diffraction peak of $\mathrm{Ca}(\mathrm{OH})_{2}$ had decreased, and the amount of C-S-H gels had increased. This is because the pozzolanic activity of the active $\mathrm{SiO}_{2}$ and $\mathrm{Al}_{2} \mathrm{O}_{3}$ in the GTS powder had been activated, and the secondary hydration reaction consumed the $\mathrm{Ca}(\mathrm{OH})_{2}$. As the amount of C-S-H gels increased, the SSA of the charged gel particles increased as well, which had enhanced the physical adsorption of chloride ions [23, 24], thereby its ability to solidify chloride ions was better than that of pure OPC, 

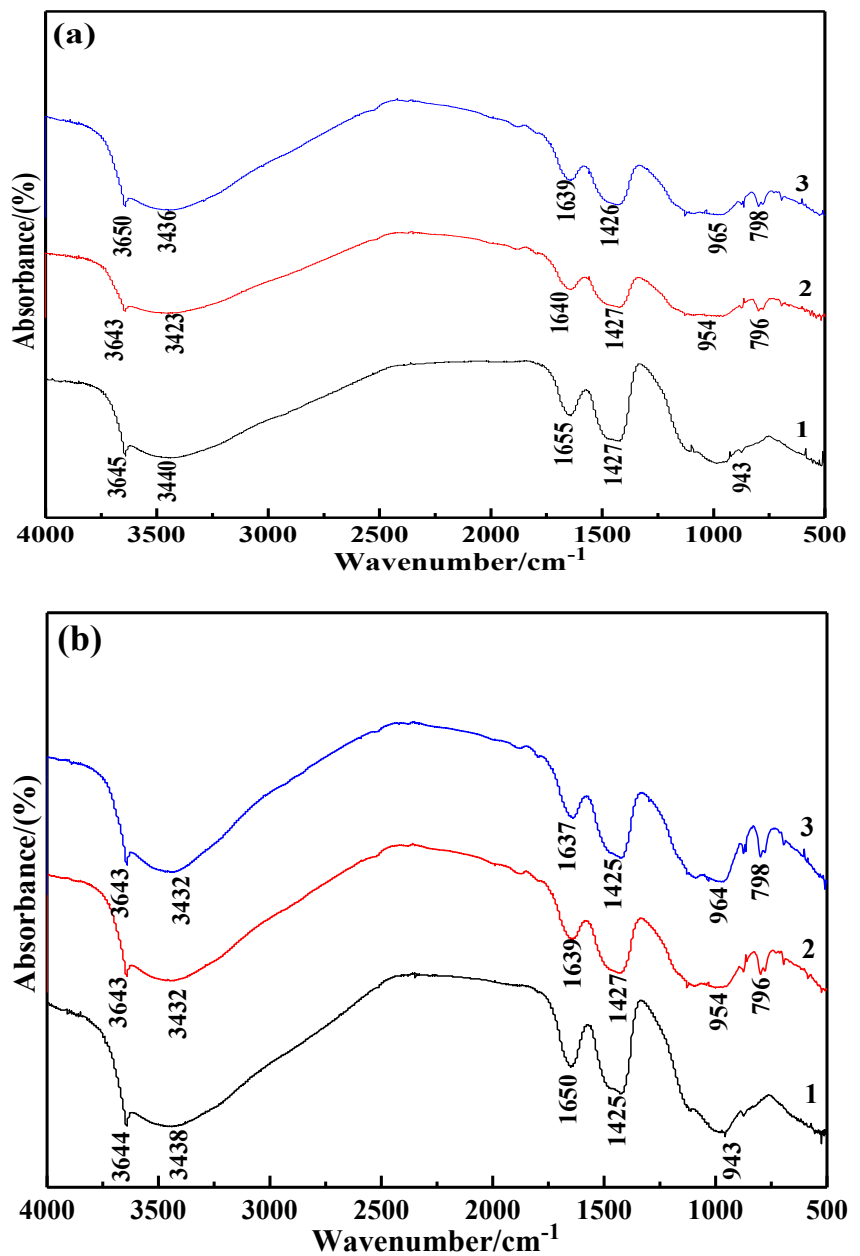

Figure 6. FT-IR patterns of hydration products of composite cementitious materials at various ages. (a)-3d; (b)-56d; (1)-OPC; (2)mechanically activated GTS powder; (3)-thermally activated GTS powder.

and this is consistent with the phenomenon in Fig. 4 that the amount of solidified chloride ions of different cementitious materials varied with the incorporation of different GTS powder.

\subsection{FT-IR analysis}

Fig. 6 is a comparison of the FT-IR analysis of the $3 \mathrm{~d}$ and $28 \mathrm{~d}$ hydrated products of the GTS-incorporated cementitious material samples and the blank samples, it can be seen from the Fig. 6 that below 1000 $\mathrm{cm}^{-1}$ there were differences between the GTS-incorporated cementitious material samples and the blank samples of different ages, and the rest of the spectrum were basically the same. It can be seen from Fig. 6(a) and Fig. 6 (b) that as the degree of hydration deepened, the position of the absorption peaks gradually shifted toward the smaller wave number direction, and the absorption peaks were gradually strengthened; this indicates that the silicon oxygen tetrahedra of the mineral particles in the GTS powder were gradually dissociating, producing high polymerization degree products such as C-S-H gels and AFt. In the $28 \mathrm{~d}$ age chart, stretching vibration frequency of the absorption peak of the samples containing thermally activated GTS powder slowed down and the gradually became sharper, which indicates that the silicate minerals in the hardening system of pure OPC samples became more complicated and the amount of C-S-H gels and AFt prod-
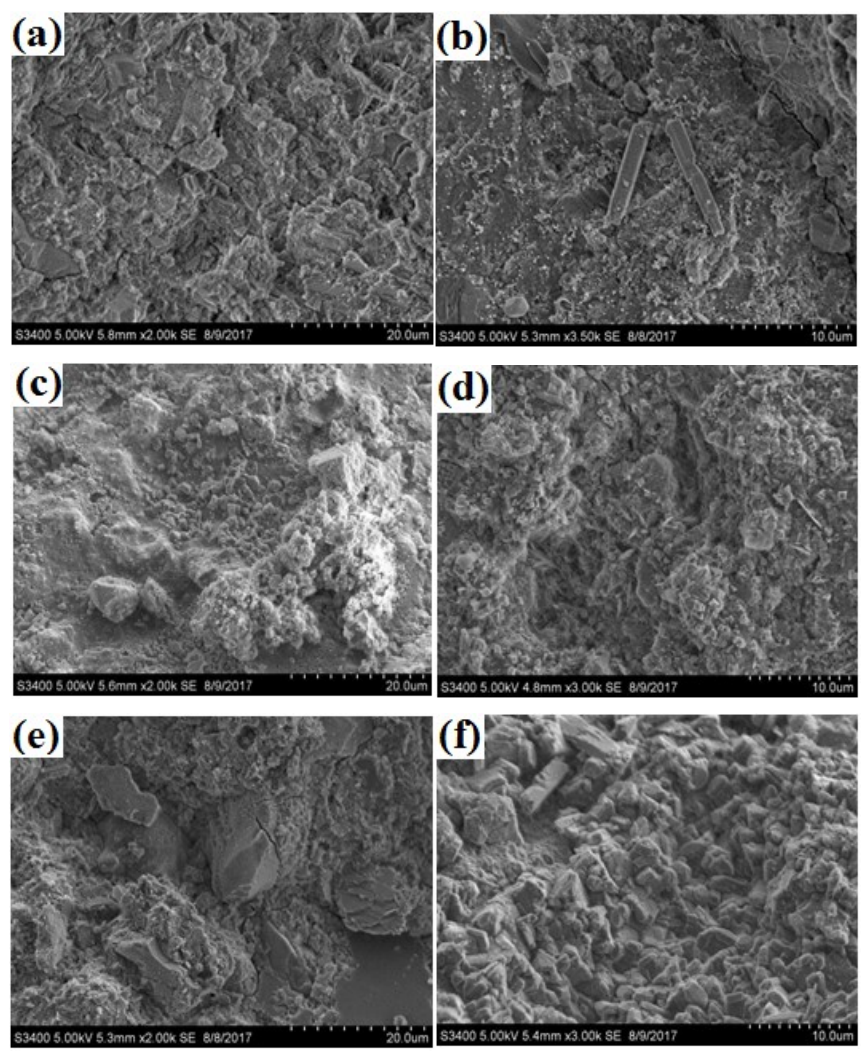

Figure 7. SEM photos of composite cementitious materials at various ages. (a) and (b)-OPC; (c) and (d)-mechanically activated GTS powder; (e) and (f)-thermally activated GTS powder

ucts increased. In the $28 \mathrm{~d}$ age chart, the absorption peak near $3644 \mathrm{~cm}^{-}$ ${ }^{1}$ is the stretching vibration of the $\mathrm{O}-\mathrm{H}$ bond in calcium hydroxide, and the absorption peaks at $3432 \mathrm{~cm}^{-1}$ and $1640 \mathrm{~cm}^{-1}$ are the bending vibration of $\mathrm{H}_{2} \mathrm{O}$, indicating that free water had participated in the hydration reaction and produced gels or substances containing crystal water; the peak at $1425 \mathrm{~cm}^{-1}$ is an absorption peak of hydration product C-S-H gels, the peak near $1000 \mathrm{~cm}^{-1}$ is the asymmetric stretching vibration of $\mathrm{Si}-\mathrm{O}(\mathrm{Al})$ bond [25], the Si-O bond stretching vibration frequency of siloxane oxygen tetrahedron groups increased with the increase of the polymerization degree. The peak wave numbers of the samples containing GTS powder are $954 \mathrm{~cm}^{-1}$ and $964 \mathrm{~cm}^{-1}$, while for the pure OPC, the corresponding peak wave number is $943 \mathrm{~cm}^{-1}$; an obvious convex absorption peak appears near $798 \mathrm{~cm}^{-1}$, which is not found in the cement sample. According to the analysis, the absorption peak is the bending vibration of $\mathrm{Si}-\mathrm{O}$ bond in $\mathrm{AFt}$, which is a quartz-containing mineral in the GTS powder; it indicates that more Si-O bonds in GTS powder had been broken as the hydration age increased, the bond energy was reduced, and the GTS powder had fully reacted, producing more AFt and C-S-H gels. The peaks at $964 \mathrm{~cm}^{-1}$ are the absorption peaks of silicate, Si-O bond, and C-S-H gels [26]. Comprehensive analysis shows that the structure of the silicate in the hydrated products of cementitious materials containing activated GTS powder was quite complex, there were many products such as C-S-H gels and AFt that can absorb the chloride ions, and meanwhile the rich hydration products can well fill in the slurry and improve its compactness, reducing the transmission efficiency of free chloride ions in the pores, thereby making the hardened slurry have a good effect on the solidification of chloride ions, and this might be a factor that can improve the ability of OPC materials to solidify the chloride ions. 


\subsection{SEM analysis}

Fig. 7 is a comparison of the SEM photographs of $3 \mathrm{~d}$ and $28 \mathrm{~d}$ samples of cementitious materials mixed with GTS powder activated by different activation methods and the paste samples of pure OPC. From Fig. 7(b) the $28 \mathrm{~d}$ age chart we can see that there were flaky $\mathrm{Ca}(\mathrm{OH})_{2}$ in the paste samples of pure OPC, which were not found in (d) and (f) of the samples containing activated GTS powder. This is because the secondary pozzolanic effect of the activated powder material in the GTS powder had been exerted, which is consistent with the reduction of $\mathrm{Ca}(\mathrm{OH})_{2}$ in the XRD spectrum. From Fig. 7 (d) and Fig. 7 (f) we can indistinctly see that the needle-shaped AFt and C-S-H gels were interspersed and intertwined, and the unreacted fine GTS particles filled in the gaps; in contrast, the porous structure of the paste sample containing mechanically activated GTS powder was more complete than that of the paste sample of pure OPC. In Fig. 7 (c) we found a large amount of aggregated flocculent C-S-H gels which had completely capsulated the AFt, analysis shows that the reactivity of thermally activated tailings powder was enhanced, the amount of active $\mathrm{SiO}_{2}$ and $\mathrm{Al}_{2} \mathrm{O}_{3}$ in the powder had increased, which promoted the secondary hydration, improving the slurry structure of the GTS -incorporated cementitious materials, lowering the porosity, refining the porous structure and improving the compactness, as a result, a dense and complete hardened slurry system had been formed, which had promoted the chloride ions solidification of the paste samples of the cementitious materials; and the enhanced mechanical properties of the mortar blocks had also confirmed this phenomenon from another perspective. In addition, in the hydration products, there were more C-S-H gels which can adsorb chloride ions, and the active components in unreacted GTS can adsorb $\mathrm{Cl}^{-}$as well [15], meanwhile the participation of active GTS powder in the reaction had provided conditions for the combination of $\mathrm{C}_{3} \mathrm{~A}, \mathrm{C}_{4} \mathrm{AF}$ and chloride ions to form FS, which had enhanced the solidification effect on $\mathrm{Cl}^{-}$as well.

\section{CONCLUSIONS}

(1) When mechanically activated tailings powder and thermally activated tailings powder had been added into the OPC, the addition of thermally activated tailings powder had an obvious effect on the solidification of chloride ions, and the effect of tailings powder had been exerted in the later stage of the hydration reaction. In the tailings powder, there are many active $\mathrm{SiO}_{2}$ and $\mathrm{Al}_{2} \mathrm{O}_{3}$ that have an important role in promoting the chemical combination of $\mathrm{C}_{3} \mathrm{~A}, \mathrm{C}_{4} \mathrm{AF}$ and other minerals in the OPC material with chloride ions to form FS.

(2) GTS containing rich silicon-aluminum raw materials was ground for $60 \mathrm{~min}$ and then thermally activated at $750^{\circ} \mathrm{C}$, its reactivity had been activated, the content of active $\mathrm{SiO}_{2}$ and $\mathrm{Al}_{2} \mathrm{O}_{3}$ in the mineral had increased, which had effectively promoted the secondary hydration of the active tailings powder.

(3) The GTS-incorporated cementitious materials can generate more hydration products $\mathrm{C}-\mathrm{S}-\mathrm{H}$ gels and $\mathrm{AFt}$ that can absorb the chloride ions, this had enhanced the ability to solidify chloride ions while improving the compactness of the samples.

\section{ACKNOWLEDGMENTS}

The authors gratefully acknowledge financial support from China Postdoctoral Science Foundation (2016M602082), supported by Natural Science Foundation of Hebei Province (E2018402119), supported by Natural Science Foundation of Shaanxi Province (2019JLM-49), supported by Shaanxi Science and Technology Benefit People Project (2018ZY-HM-01), supported by Science and Technology Research Project of Higher Education Universities in Hebei Province (ZD2016014, QN2016115), supported by Comprehensive Utilization of Tailing Resources Key Laboratory of Shaanxi Province (2017SKY-
WK008), supported by Jiangxi Postdoctoral Daily Fund Project (2016RC30), supported by Jiangxi Postdoctoral Research Project (2017KY19), supported by State Key Laboratory of Solid Waste Reuse for Building Materials (SWR-2019-008).

\section{REFERENCES}

[1] Thomas M D A, Bamforth P B., Cement and Concrete Research, 4(29), 487 (1999).

[2] Tang L, Nilsson L O., Cement and Concrete Research, 23(2), 247 (1993).

[3] Ge Y, Zhu Y., Corrosion of steel bars in concrete and cathodic protection, Chemical Industry Press, Beijing, 2007.

[4] Liang Z B., Process analysis of chloride ion invading cement-based materials, Hebei University of Technology, Tianjin, 2012.

[5] Zibara H. Binding of external chloride by cement pastes, University of Toronto, Toronto, 2001.

[6] Gou M F, Guan X M, Zhang H B. Study on the ability of ettringite to combine chloride ions [J]. Materials Review, 2013, 27(5): 136139.

[7] Yu H F, Weng Z C, Sun W., Journal of the Chinese Ceramic Society, 35(6), 801 (2007).

[8] Boğa A R, Topçu I B., Construction and Building Materials, 31, 258 (2012).

[9] Chahal N, Siddique R, Rajor A., Construction and Building Materials, 28(1), 351 (2012).

[10]Oh B H, Cha S W, Jang B S, Jang S Y., Nuclear Engineering and Design, 212(1-3), 221 (2002).

[11]Yazıcı H., Construction and Building Materials, 22(4), 456 (2008).

[12]Amin, N., Advances in Cement Research, 2011, 23(2), 75 (2011).

[13]Amin N., Journal of Solid Waste Technology and Management, 36(3), 164 (2010).

[14]Teng S, Lim T Y D, Divsholi B S., Construction and Building Materials, 40, 875 (2013).

[15]Zhang D, Ghouleh Z, Shao Y X., Journal of $\mathrm{CO}_{2}$ Utilization, 21, 119 (2017).

[16]Guan H T, Liu S H, Duan Y P, Cheng J., Cement and Concrete Composites, 28(5), 468 (2006).

[17]Paul S C, van Rooyen A S, van Zijl G P A G, Petrik L F., Construction and Building Materials, 189, 1019 (2018).

[18]Schmidt W, Alexander M, John V., Cement and Concrete Research, 114, 103 (2018).

[19]Wang B M, Zhao R Y., Construction and Building Materials, 161, 715 (2018).

[20]Rao M J, Tang W, Zhou W, Kong Y N, Liu S H., Advances in Materials Science and Engineering, 20, 1 (2016).

[21]Cao Q, Tan K F., Journal of Wuhan University of Technology, 31(6), 24 (2009).

[22]Arya C, Buenfeld N R , Newman J B., Cement and Concrete Research, 20(2), 291 (1990).

[23]Zibara H, Hooton R D, Thomas A, Stanish K., Cement and Concrete Research, 38(3), 422 (2008).

[24]Wang X G, Shi C J, He F Q, Yuan Q, Wang D H, Huang Y, Wang Q L., Journal of the Chinese Ceramic Society, 41(2), 187 (2013).

[25]Hanna R A, Barrie P J, Cheeseman C R, Hill C D, Buchler P M, Perry R., Cement and Concrete Research, 25(7), 1435 (1995).

[26]Yu P, Kirkpatrick R J, Poe B, McMillan P F, Cong X D., Journal of the American Ceramic Society, 82(3), 742 (1999). 